\title{
Prenatal Care for Adolescents and attributes of Primary Health Care ${ }^{1}$
}

\author{
Maria Cristina Barbaro ${ }^{2}$ \\ Angelina Lettiere ${ }^{3}$ \\ Ana Márcia Spanó Nakano ${ }^{4}$
}

Objective: evaluate prenatal care for adolescents in health units, in accordance with the attributes of Primary Health Care (PHC) guidelines. Method: quantitative study conducted with health professionals, using the Primary Care Assessment Tool-Brazil to assess the presence and extent of PHC attributes. Results: for all the participating units, the attribute Access scored $\leq 6.6$; the attributes Longitudinality, Coordination (integration of care), Coordination (information systems) and Integrality scored $\geq 6.6$, and the Essential Score $\leq 6.6$. Comparing basic units with family health units, the attribute scores were equally distributed; Accessibility scored $\leq 6.6$, the others attributes scored $\geq 6.6$; however, in the basic units, the Essential Score was $\leq 6.6$ and, in the family health units, $\geq 6.6$. Conclusion: expanding the coverage of family health units and the training of professionals can be considered strategies to qualify health care.

Descriptors: Primary Health Care; Pregnancy in Adolescence; Women's Health; Prenatal Care, Health Personnel.

\footnotetext{
${ }^{1}$ Paper extracted from master's thesis "Prenatal care for adolescent mothers conducted in the primary care network of the city of Ribeirão Preto and attributes of primary healthcare from the perspective of health professionals", presented to Escola de Enfermagem de Ribeirão Preto, Universidade de São Paulo, WHO Collaborating Centre for Nursing Research Development, Ribeirão Preto, SP, Brazil.

2 Master's student, Escola de Enfermagem de Ribeirão Preto, Universidade de São Paulo, WHO Collaborating Centre for Nursing Research Development, Ribeirão Preto, SP, Brazil.

${ }^{3}$ Doctoral student, Escola de Enfermagem de Ribeirão Preto, Universidade de São Paulo, WHO Collaborating Centre for Nursing Research Development, Ribeirão Preto, SP, Brazil.

${ }^{4}$ PhD, Full Professor, Escola de Enfermagem de Ribeirão Preto, Universidade de São Paulo, WHO Collaborating Centre for Nursing Research Development, Ribeirão Preto, SP, Brazil.
}

Corresponding Author:

Ana Márcia Spanó Nakano

Universidade de São Paulo. Escola de Enfermagem de Ribeirão Preto Departamento Materno-Infantil e Saúde Pública

Av. Bandeirantes, 3900

Bairro: Monte Alegre

CEP: 14040-902, Ribeirão Preto, SP, Brasil

E-mail: nakano@eerp.usp.br
Copyright (c) 2014 Revista Latino-Americana de Enfermagem This is an Open Access article distributed under the terms of the Creative Commons Attribution Non-Commercial License (CC BY-NC).

This license lets others distribute, remix, tweak, and build upon your work non-commercially, and although their new works must also acknowledge you and be non-commercial, they don't have to license their derivative works on the same terms. 


\section{Introduction}

In Brazil, in $2007,71 \%$ of live-borns were children of women aged between 15-29 years; live-borns of women aged between 15-19 years accounted for about $20 \%$ of all births ${ }^{(1)}$. It can be observed that, in $2000-$ 2009 , the number of adolescents giving birth dropped $34.6 \%$, probably reflecting family planning policies promoted by health professionals(2).

Teenage pregnancy is a complex issue; considering that the adolescent body is not always physiologically prepared for the development of pregnancy, the risk to the mother and child health is real(3). Besides the biological aspect, other risks exist, including: 1) social situation; 2) lack of information; and 3) emotional unreadiness. All of these can cause difficulties in the puerperal pregnancy cycle and in the care for the newborn and the mother ${ }^{(4)}$.

In this sense, Primary Health Care (PHC) can be defined as: set of values, principles, sustainability, intersectoriality and social participation. Primary Health Care attributes are: 1) access to first contact, 2) integrality, 3) longitudinality, 4) coordination, 5) family and community orientation and 6) cultural competence ${ }^{(5)}$; these attributes constitute essential qualities that are challenging to reach ${ }^{(6)}$. The more a health service is geared towards developing this set of attributes, the more it becomes capable of providing comprehensive community care from the biopsychosocial point of view(6).

When seeking the quality of Primary Health Care services, there are principles that need to be obeyed and respected, such as: i) first contact: access of people seeking health care services; ii) longitudinality: regulating contribution and consistent care given by the healthcare team, in a humane environment, observing the relationships among health teams, individuals and families; iii) integrality: the set of services that attend to the population's most common problems - regarding biological, psychological and social problems that denote the disease; and iv) coordination: the ability to ensure continuity of care ${ }^{(6)}$.

In Brazil, observing the context of health services and the specifics of its users (pregnant adolescents), it is necessary to invest in methods, managerial instruments and the organization of collective work to produce changes within the system and transform people and their practices. These seek to favor the welcoming, the bond, the contract and the autonomy of the subjects in the progressive organization of care as a strategy to transform the system.
Thus, we want to know how adolescents were attended in the prenatal primary care network, in accordance with the attributes of Primary Health Care. Therefore, we sought to evaluate the prenatal care offered to adolescents at health facilities in a city in the state of Sao Paulo, in accordance with the presence and extent of PHC attributes and with the help and experience of health professionals working in the health units.

This study is justified by the lack - in specialized literature - of research on the assessment of prenatal care utilizing PHC attributes. Elucidating this issue will provide information to guide new strategies for action and for training human resources to provide integral care to pregnant adolescents. An important contribution of this study to the health area is the possibility to observe the participation of health professionals, which through interaction with adolescents will have a better understanding of the pregnancy process, thus providing participatory and educational care.

\section{Method}

This is a descriptive and cross-sectional study with a quantitative approach; it was conducted at a district health unit that attends a large contingent of pregnant adolescents; the source of secondary data was the Declaration of Live-Born in $2010^{(7)}$. The study defines adolescents as individuals aged between 10 and 19 years $^{(8)}$. The district health services chosen were: one Basic Health District Unit (BHDU), one School-Based Health Center (SBHC), six Basic Health Units (BHU) and four Family Health Units (FHU). All of these are gateways to the system, as they offer prenatal care up to 36 weeks of pregnancy, when the adolescents are referred for further follow-up to three governmentsponsored maternities.

The study participants were selected based on the following criteria: professionals who work directly with adolescent prenatal care. In the district, 44 professionals, physicians and nurses directly attend the prenatal care of adolescents. From the 22 nurses selected, two work at $\mathrm{SBHC}$, thirteen at $\mathrm{BHU}$ and seven at FHU. Regarding the medical professionals, three work at SBHC, twelve at $\mathrm{BHU}$ and seven at $\mathrm{FHU}$, totaling 22 physicians.

All professionals were invited to participate in the study. There was one refusal, two professionals went on medical leave and five were excluded based on the following exclusion criteria: three appointments failed for interviewing, i.e. the professional could not attend three 
scheduled dates due to his service demand. Therefore, the analyzed sample consisted of 36 professionals.

By involving human beings, this study complied with the requirements established by Resolution 466/2012 of the National Health Council(9). Data collection was initiated after approval by the Research Ethics Committee at the Ribeirao Preto College of Nursing under Protocol $1188 / 2010$. After the identification of the health services and the number of professionals who met the inclusion criteria, they were invited. After the invitation had been accepted, the interview was scheduled by telephone on the day and time agreed between interviewee and interviewer. Data collection was carried out on the premises of the health services from December 2011 till March 2012. The professionals were informed about the research objectives, through the reading of the Informed Consent (IC) form by the researcher. After that, if the interviewee accepted the terms, the form was signed and the interview began. The participants received a copy of the IC, duly signed by the researcher and the interviewee.

In this study, the quality of health care to pregnant adolescents is defined as the presence and extent of the essential attributes of $\mathrm{PHC}^{(5)}$. We used the Primary Care Assessment Tool to characterize the study subjects; this tool was developed by Barbara Starfield. The instrument, based on individual assessment, evaluates the structure and process that guides the $\mathrm{PHC}^{(5)}$. Translation and validation in Brazil was carried out in 2006 by a group of researchers from the Federal University of Rio Grande do Sul. After validation, the instrument was named Primary Care Assessment Tool (PCATool-Brasil)(10). In this study, we used the professional version of the PCATool-Brazil to assess the structural aspects and the care process in the health services. Only the essential attributes of the instrument were assessed; other attributes, such as integrality of services (F), family orientation (G) and community orientation $(\mathrm{H})$ were not included because they went beyond the study focus.

An Excel database was used to store the collected data, using double data entry to eliminate possible errors. Data were processed using SPSS software, version 12.1. To analyze continuous variables related to sociodemographic characteristics and professional training, central trend (mean and median) and dispersion (standard deviation) measures were calculated. For categorical variables, proportions were calculated.

Data related to the PCATool-Brazil were analyzed statistically. For each attribute and its components, the arithmetic mean of the scores was calculated ${ }^{(5)}$. On a
Likert scale, the range of scores went from 1 to 4 . The answers were distributed as follows: "Certainly yes" (value $=4)$, "Probably yes" (value=3), "probably not" (value=2), "Certainly not" (value=1), "Don't know / cannot remember" (value=9).

After calculating the attribute scores, the essential score was calculated by finding the average score of essential attributes (sum of attribute score divided by the number of attributes), thus generating the essential PHC score. Scores $\geq 3$ indicate proper extension of each attribute (probably not - negative $=2$ and probably yes - positive=3). To transform the scores on a scale from 0 to 10 , the following formula was used: score obtained -1 (minimum value) x $10 \div 4$ (maximum value) - 1 (minimum value). Using the already mentioned formula, the scores originally ranging from 1 to 4 were transformed to a scale of 0 to 10 . The value 3 on the scale from 1 to 4 is equal to 6.6 on the new scale from 0 to $10([3-1] \times 10 \div 3=6.6)$. In this transformation, scores $\geq 6.6$ were considered high $\mathrm{PHC}$ and indicate appropriate extension of each attribute. Thus, this value was chosen because it corresponds, in the range from 1 to 4 , to score 3 ("probably yes")(11). Therefore, the instrument produces scores for each attribute and also the essential score, permitting the measuring of the degree of orientation to PHC attributes in different services and health systems ${ }^{(5)}$.

\section{Results}

The adolescent population, which includes the age group between 10 and 19 years $^{(8)}$, is estimated at 90,694 , with 45,908 males and 44,786 females ( $14.99 \%$ of total population surveyed in the city are adolescents). In this city, adolescent pregnancy corresponded to $12.4 \%$ of 8,090 births in 2010 , which is the reference year for this investigation. Of the 8,090 births, 4,478 happened in the Unified Health System (SUS), of which $18.4 \%$ were adolescents; the Northern District, with $22.2 \%$, revealed the highest frequency among the five districts of the city ${ }^{(7)}$.

In the district under analysis, we interviewed 36 health professionals, 17 physicians and 19 nurses; most respondents were female $(72.2 \%)$. The mean age was 41 years, ranging from 28 to 61 years. As regards the workplace, 20 (55.6\%) professionals work at BHU, 13 $(36.1 \%)$ at $\mathrm{FHU}$ and $3(8.3 \%)$ at SBHC.

Regarding the number of workplaces, half of the professionals work in only one health service, and the other half in two or more. Among nurses, 15 (78.9\%) 
work in only one service, and four $(21.1 \%)$ in two or more. Among physicians, three (17.7\%) work in only one service, and 14 (82.3\%) in two or more.

Regarding the year of graduation, this ranged from 1976 to 2007; more than half of the professionals graduated less than 25 years earlier, with a higher concentration in the group that graduated less than 15 years earlier. Also, 24 (66.6\%) professionals obtained a specialization degree. The number of specializations obtained was greater in the nursing team (17) when compared to the medical team (07). It is noteworthy that the specialization in family health appears only among physicians (03), as well as the family medical residency (02). Regarding nurses, most specializations were focused on public health (08). With respect to residency, it is worth noting that only the medical professionals held this medical training. In relation to stricto sensu postgraduate studies, only the nursing categories attended those courses.

About the work experience of professionals in the health care network, the average was ten years, with a minimum of six months and a maximum of 32 years. As to the time of professional experience in prenatal care, the average was 11 years, ranging from two months to 26 years. The average work experience at the health units that participated in the study was five years, varying between one month and 18 years.

Regarding PHC attributes, we present the score of attributes and the essential score of 11 health units participating in the research (BHU, SBHC, FHU). For the attribute Access to first contact (accessibility), the score was 3.5, showing professionals' low evaluation of the PHC attribute at the units they belonged to. The other attributes obtained high scores, i.e., scores $\geq 6.6$ indicating a strong presence and an appropriate range for each attribute. The essential score was 6.5 (Table 1).

The analysis of attributes was also performed by considering two different groups, one group of professionals belonging to Basic Health Units and School-Based Health Centers and another group of professionals belonging to Family Health Units. Access to first contact (accessibility) in PHC BHU/SBHC scored 3.4, which shows professionals' low evaluation of the PHC attributes at the BHU they belong to. Other attributes obtained high scores, i.e., $\geq 6.6$, considered a high score for $\mathrm{PHC}$, indicating strong presence and an appropriate range for each attribute. The essential score was 6.4 (Table 1 ).

Access to first contact (accessibility) in FHU scored 3.6, which shows professionals' low evaluation of the PHC attributes at the FHU. Other attributes obtained high scores, i.e., $\geq 6.6$, considered a high score for $\mathrm{PHC}$, indicating a strong presence and an appropriate range for each attribute. The Essential score was 6.6 (Table 1).

It seems that, regardless of the care models at the health services ( $\mathrm{BHU}$ and $\mathrm{FHU}$ ), most attributes had strong presence and extent, i.e., scores $\geq 6,6$. Only the attribute Access to first contact (accessibility) scored low. When evaluating the essential score, only the model of FHU showed professionals' high evaluation regarding the $\mathrm{PHC}$ attributes. The $\mathrm{BHU} / \mathrm{SBHC}$ models showed professionals' lower evaluation regarding the attributes of PHC. Throughout the analysis of all models, i.e., in all health units investigated, the essential score showed professionals' lower evaluation regarding the PHC attributes (Table 1).

Table 1 - Scores of attributes and essential score of Primary Health Care Services in Basic Health Care Units, Northern District, City of Ribeirão Preto. Ribeirão Preto, SP, Brazil, 2012

\begin{tabular}{|c|c|c|c|}
\hline Primary Health Care Attributes & Units $(n=36)$ & $\begin{array}{l}\text { Basic Health Care Units/School- } \\
\text { Based Health Centers }(n=23)\end{array}$ & Family Health Units $(n=13)$ \\
\hline Access to first contact & 3.5 & 3.4 & 3.6 \\
\hline Longitudinality & 7.1 & 6.8 & 7.6 \\
\hline Coordination (integrated care) & 6.8 & 6.8 & 7.0 \\
\hline Coordination (information system) & 7.8 & 7.8 & 7.8 \\
\hline Integrality (available services) & 7.2 & 7.3 & 6.9 \\
\hline Essential score & 6.5 & 6.4 & 6.6 \\
\hline
\end{tabular}

\section{Discussion}

Health systems that are guided by the principles of PHC show better health levels. Although these levels were checked primarily in developed countries(11), in the few studies conducted in non-developed countries, evidence of the positive impact of PHC's guidelines in health systems was also observed ${ }^{(12)}$. 
Today, there are few studies investigating the effectiveness of PHC attributes in more vulnerable population groups, such as pregnant adolescents. These studies seek to achieve a better quality of care in prenatal services for early pregnancy. The existence of few studies about prenatal evaluation from the perspective of $\mathrm{PHC}$ attributes hinders the comparison of findings; on the other hand, this situation confirms the relevance of this research.

The quality of care measured based on PHC attributes in the prenatal services for adolescents in 11 health units in the city showed a low score (3.5) for the attribute Access to first contact (accessibility), and high PHC scores for the other attributes: Longitudinality, Coordination (information systems), Coordination (integration of care) and Integrality (available services); these scored $\geq 6.6$, which indicates proper extension of each attribute. However, the essential score was 6.5 , showing professionals' low evaluation of the PHC attributes at the 11 health units.

The attribute Access to first contact can be understood as the users' "gateway" to a place where they can express their needs, and somehow shows their course through the system, searching a solution for their needs ${ }^{(13)}$. In the investigated services, adolescent pregnancy has become a frequent demand. Besides the analysis of these indicators of prenatal quality, the limited professional guidance in the surveyed units about Access to first contact refers to the fact that attention to pregnant adolescent lacks reorientation of health services to provide accessibility and acceptability, which are the access dimensions ${ }^{(14)}$ of pregnant women, without any distinction; attention to their specific needs tends not to be contemplated neither in the practice, nor in manuals or service protocols aimed at the control of risks to reduce maternal and infant complications.

In the analysis to measure the presence and extent of each PHC attribute, the different models of health care utilized in $\mathrm{BHU} / \mathrm{SBHC}$ and $\mathrm{FHU}$ have been highlighted in the literature. Many studies show positive impacts of Family Health Teams (FHT) on the Brazilian health system, such as: greater coverage of $\mathrm{FHT}$, lower child mortality, greater promotion of equity, increased appropriateness regarding supply and use of FHT health actions, and higher quality of prenatal care and childcare(11).

In the analysis of the two healthcare models, $\mathrm{BHU}$ and SBHC, the quality of care measured according to PHC attributes in prenatal services for adolescents showed that Access to first contact scored low in both models:
BHU (3.4) and FHU (3.6). Other attributes received high scores. The low score obtained for the attribute Access to first contact refers to the weaknesses in the reception of pregnant adolescents, as emphasized earlier.

The attribute coordination (information systems) obtained the highest score for both models of care, which implies good presence and extent of this attribute, regardless of being $\mathrm{BHU}$ or FHU. Similar results were also observed in other studies using the PCATool professional version(11).

As regards the PHC attributes: Longitudinality and Integrality, albeit with scores higher than 6.6, in both models, it is important to ponder about the differences in the values assigned, which shows the potential and limitations of each care model for these attributes. Concerning the attribute longitudinality (6.8 for $\mathrm{BHU}$ and 7.6 for $\mathrm{FHU}$ ), one can reflect about the potential of the principles ruling the Family Health Program (FHP). The longitudinality implies a therapeutic relationship, characterized by responsibility of health professionals and confidence of the patient ${ }^{(15)}$. Such characteristics are important to further the effectiveness of care follow-up. In UBS, when users are referred to other services, they are not sure they will return to the same professional who provided the health care the first time.

Contrary to what one might expect for the attribute integrality, the comparison of scores between BHU (7.3) and FHU (6.9) showed higher scores among the former. Considering the integrality of care as one of the guidelines of the Brazilian public health system (SUS), we propose the organization of services and implementation of health practices (integrated by a set of strategies for prevention, promotion, curative and rehabilitation) in the entire healthcare service ${ }^{(4)}$ chain. The FHP has the fundamental conditions to introduce changes in health practices from the perspective of comprehensive care; however, this does not happen spontaneously. Professionals who form a team have different principles, values and interests that can interfere in the organization and production of services. In the context of the Family Health Units sampled, it is important to consider that the favorable moments for providing services might be impaired by existing conditions; as an example of the local reality, not all FHU have proper premises for vaccination. This could justify lower scores given by professionals to this attribute when compared to BHU scores.

The epistemological core that drives the FHP and its operating field contain potentialities that justify the strong essential score of 6.6 (value that aggregates all 
PHC attributes) found in the care model of FHU that was higher than that found in the model for BHU (6.4), as observed in this study. This finding corroborates other studies that used the PCATool-Brazil (version for health professional) in order to evaluate $\mathrm{PHC}$ services and compared FHU with BHU.

This instrument was applied in $104 \mathrm{BHU}$, to the following health professionals: pediatricians, gynecologists, obstetricians, general practitioners and nurses, being $53 \mathrm{FHU}$ and 51 traditional units, in Curitiba(16). The results indicated that, for $\mathrm{FHU}$, the mean scores and the attributes' percentage are high and significantly higher than in traditional units (TU). The same occurs when these attributes are summarized in the essential scores: traditional units obtained a borderline score of 6.6 and the FHU obtained a higher score, indicating greater presence and extent of the PHC attributes in the latter model.

A study ${ }^{(11)}$ that sought to compare the quality of healthcare for adults among different types of PHC services in Porto Alegre, using the PCATool instrument (version for healthcare professionals), verified that the services oriented by the Family Health Strategy model, when compared to those of BHU, are significantly more attached to the guiding principles of the PHC. The study was conducted with a sample of 340 professionals (physicians and nurses) who worked in $26 \mathrm{BHU}$ and in $31 \mathrm{FHU}$, randomly selected, representing $50 \%$ of the city's units. The attributes integrality and community orientation obtained the most significant difference when comparing scores; the UBS presented the lowest scores for these attributes. The attribute integrality (capacity of recognizing common health problems in the population) and the attribute community orientation (knowledge to recognize health needs of the community and the appropriate community approach) were used to evaluate the performance of professional activities and were less present in UBS.

\section{Conclusions}

Prenatal care is an important strategy to establish a monitoring process for the health of pregnant women and their children. Particularly among adolescents, early motherhood is of high risk to the mother and child, especially for those belonging to lower income classes. The presence and extent of PHC attributes are very important to achieve adherence and care continuity for adolescents, which are aspects that in our reality have shown to be unfavorable indicators of quality.
In this study, the quality of health care for pregnant adolescents is understood as the presence and extent of the essential attributes of PHC, which are evaluated through the experience of health professionals. In that sense, we conclude that, regardless of models of care units (BHU and $\mathrm{FHU}$ ), the attributes showed a strong presence and extent with scores $\geq 6.6$; only the attribute Access to first contact (accessibility) scored below the cut-off point.

When evaluating the essential score, only the FHU model presented a higher degree of adherence to PHC guidelines. The best essential score at FHU's mainly reflects better qualifications to develop practices that enhance health promotion and disease prevention in intersectoral actions, according to PHC principles. This finding indicates that it is necessary to implement new units of Family Health Care, or to review the existing model in traditional units.

Given the results, it is important to emphasize that the education of health professionals should be more comprehensive and contextualized; thus, physicians and nurses working in prenatal care for adolescents will acquire the ability to: i) recognize the context of communication and welcoming; ii) listen; iii) recognize and understand differences in culture and values; and, iv) find solutions within the context of the patient's reality. Additionally, we can include multiprofessional teamwork and coordination with other sectors.

This study refers to the difficulty of pregnant adolescents to access the municipal health services; it also refers to the need to extend the research to other regions of the city, which would permit the assessment of PHC attributes in the municipal public service network.

\section{References}

1. Castro JA, Aquino LMC, Andrade CC. Juventude e políticas sociais no Brasil. Brasília; Ipea; 2009.

2. Ministério da Saúde. (BR). Brasil acelera a redução da gravidez na adolescência. Brasília: Ministério da Saúde; 2010.

3. Levandowski DC, Piccinini CA, Lopes RCS. Maternidade adolescente. Estud Psicol. 2008;25(2):251-63.

4. Ministério da Saúde (BR). Secretaria de Atenção em Saúde. Departamento de Ações Programáticas Estratégicas. Diretrizes nacionais para a atenção integral à saúde de adolescentes e jovens na promoção, proteção e recuperação da saúde. Brasília: Ministério da Saúde; 2010. 
5. Ministério da Saúde (BR). Manual do instrumento de avaliação da atenção primária à saúde: Primary Care Assessment Tool PCATool-Brasilia: Ministério da Saúde; 2010.

6. Starfield B. Atenção primária: equilíbrio entre necessidades de saúde, serviços e tecnologia. Brasília: Organização das Nações Unidas para a Educação, a Ciência e a Cultura, Ministério da Saúde; 2002. 726 p.

7. Ministério da Saúde (BR). Secretaria Municipal de Ribeirão Preto. Sistema de Coleta de Dados e Análise de Estatísticas Vitais (SICAEV). Brasília: Ministério da Saúde; 2010.

8. Ministério da Saúde (BR). Secretaria de Atenção à Saúde. Área de Saúde do Adolescente e do Jovem. Marco legal: saúde, um direito de adolescentes. Brasília: Ministério da Saúde; 2005.

9. Ministério da Saúde (BR). Resolução nº 466/2012. Diretrizes e Normas Regulamentadoras de Pesquisa Envolvendo Seres Humanos. Brasília : Conselho Nacional de Saúde; 2012.

10. Harzheim E, Starfield B, Rajmil L, Álvarez-Dardet C, Stein AT. Consistência interna e confiabilidade da versão em português do Instrumento de Avaliação da Atenção Primária (PCATool-Brasil) para serviços de saúde infantil. Cad Saúde Pública. 2006;22(8):1649-59.

11. Castro RCL, Knauth DR, Harzheim E, Haiser L, Duncan BB. Avaliação da qualidade da atenção primária pelos profissionais de saúde: comparação entre diferentes tipos de serviços. Cad Saúde Pública. 2012;28(9):1772-84.

12. Macinko J, Starfield B, Erinosho T. The impact of primary healthcare on population health in low and middle income countries. J Ambul Care Manage. 2009;32:150-71.

13. Jesus WLA, Assis MMA. Revisão sistemática sobre o conceito de acesso nos serviços de saúde: contribuições do planejamento. Ciênc Saúde Coletiva. 2010;15(1):161-70.

14. Sanchez RM, Ciconelli RM. Conceitos de acesso à saúde. Rev Panam Salud Publica. 2012;31(3):260-8.

15. Cunha EM, Giovenella L. Longitudinalidade/ continuidade do cuidado: identificando dimensões e variáveis para a avaliação da Atenção Primária no contexto do sistema público de saúde brasileiro. Ciênc Saúde Coletiva. 2011;16(1):1029-42.

16. Chomatas ERV. Avaliação da presença e extensão dos atributos da atenção primária na rede básica de saúde no município de Curitiba, no ano de 2008. [Dissertação Mestrado]. Porto Alegre: Universidade Federal do Rio Grande do Sul; 2009. 95 p. 